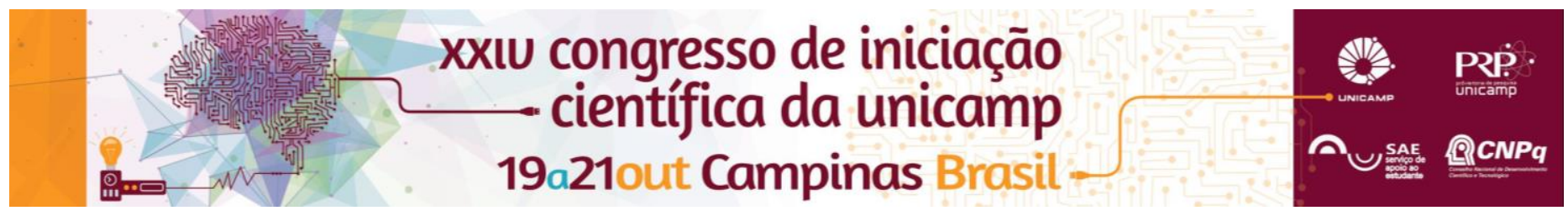

\title{
Produção científica sobre a formação do nutricionista nos últimos 20 anos
}

\author{
Autores: Joseane Bessa Araujo*, Marta Fuentes Rojas
}

\begin{abstract}
Resumo
A formação do nutricionista atualmente tem como base uma formação generalista, humanista e crítica, no entanto, o que se observa é uma formação que continua prezando a abordagem biológica. Estudo de revisão bibliográfica, cujo objetivo foi conhecer as discussões sobre os avanços e desafios na formação do nutricionista, nos últimos 20 anos. A busca foi realizada na base de dados Scielo, Lilacs e Pubmed, com as seguintes palavras chaves: formação do nutricionista, formação em nutrição, currículo do curso de nutrição, ensino superior em nutrição. Os estudos confirmam que apesar das mudanças ao longo dos anos, a abordagem biológica continua muito presente na grade curricular do curso.
\end{abstract}

\section{Palavras-chave: \\ Formação do nutricionista, Formação em nutrição, Currículo do curso de nutrição.}

\section{Introdução}

A formação do profissional nutricionista baseia-se em uma formação generalista, humanista e crítica marcada pelos princípios éticos e refletindo sobre a realidade econômica, política, social e cultural das comunidades, prezando por uma formação com abordagem biológica e humana dando a essas duas abordagens igual importância na grade curricular (RECINE, 2014). Porém a formação em nutrição é composta por disciplinas básicas e profissionalizantes (CANESQUI, 2005). Esse cenário composto por disciplinas biológicas e técnicas continua presente nos cursos de nutrição (RECINE, 2012). Diante desse cenário se questiona a qualidade do processo de formação, considerando que as disciplinas das ciências biológicas estão presentes de forma predominante no curso em detrimento das disciplinas de ciências humanas. Assim, um dos desafios no currículo superior em nutrição é a valorização da abordagem humanista para que este profissional consiga atuar nas diferentes dimensões que envolvem a alimentação e a nutrição (RECINE, 2014). Isto levou a pensar o que os estudos apontam sobre a formação deste profissional, considerando as mudanças propostas para os profissionais da saúde? Portanto o objetivo foi conhecer as discussões sobre os avanços e desafios na formação do nutricionista a partir dos debates dos estudos.

\section{Resultados e Discussão}

Estudo de revisão de caráter qualitativo. A busca foi realizada na base de dados Scielo, Lilacs e Pubmed, associando as seguintes palavras chaves: formação do nutricionista, formação em nutrição, currículo do curso de nutrição, ensino superior em nutrição. $O$ critério de busca foi: palavras chaves, período de estudo e o acesso aos artigos na base de dados ou nos sites das revistas. O período escolhido para busca foi a produção nos últimos 20 anos. Após levantamentos dos dados foram selecionados 23 artigos, para análise. Os estudos afirmam que a formação do nutricionista sofreu diversas mudanças ao longo dos anos, porém a abordagem biológica continua muito presente na grade curricular deste curso. Em comparação, as disciplinas de ciências humanas não possuem espaço significativo no curso, mesmo que essas disciplinas sejam apontadas, pelos estudos, como de extrema importância para a formação do nutricionista visto que é exigido deste profissional postura crítica diante das mudanças que ocorrem na sociedade, principalmente, em assuntos relacionados à saúde e alimentação. O conhecimento das disciplinas de ciências humanas se faz necessário para atuação profissional na área de Saúde Pública e inserção mais participativa no Programa Saúde da Família. Outras críticas são feitas ao mercado de trabalho, especialmente, no que se refere ao trabalho do nutricionista em Unidade de Alimentação e Nutrição dado que nesta área o nutricionista parecer exercer mais um papel de administrador do que de nutricionista, perdendo assim sua identidade quanto profissional. Em contrapartida outros estudos apresentam ideias para solucionar alguns desafios da formação do nutricionista, por exemplo, incorporação das disciplinas de ciências humanas desde o primeiro ano de formação, estágios em conjunto com outros cursos, promover trabalhos de campo com a comunidade desde o início do curso.

\section{Conclusões}

Existem muitos desafios a serem superados na formação do nutricionista para construir a identidade deste profissional, promover o ensino específico aliado ao ensino político e participação social. Mesmo que algumas atitudes já estejam sendo pensadas e praticadas 0 caminho para melhoria do curso ainda é longo e necessita da cooperação de estudantes, docentes e universidade.

\section{Agradecimentos}

\section{Ao SAE/Unicamp pelo apoio financeiro.}

CANESQUI, A. M. (org.) Antropologia e nutrição: um diálogo possível. Rio de Janeiro: Editora FIOCRUZ, 2005. 306p. Disponível em<http://books.scielo.org/id/v6rkd>. Acessado em 06. Mar.2015

RECINE, E. et al . A formação em saúde pública nos cursos de graduação de nutrição no Brasil. Rev. Nutr., Campinas, v. 25, n. 1, p. 21-33, Fev. 2012. Acessado em 06 Set. 2015. Disponível em

http://www.scielo.br/scielo.php?script=sci_arttext\&pid=S1415

$52732012000100003 \& \operatorname{lng}=$ en\&nrm=iso>. Acessado em 06 Set.2015.

RECINE, E. et al . Saúde coletiva nos cursos de Nutrição: análise de projetos político-pedagógicos e planos de ensino. Rev. Nutr.,Campinas , v. 27, n. 6, p 747-760, Dec. 2014.Disponível

<http://www.scielo.br/scielo.php?script=sci_arttext\&pid=S1415

$52732014000600747 \& \operatorname{lng}=$ en\&nrm=iso>. Acessado em 06 Set. 2015. 